\title{
Las razones detrás (de la ausencia) del bandolerismo. El caso de la intendencia de Arequipa a fines del virreinato $(1780-1824)^{*}$
}

\author{
por \\ César Belan ${ }^{1}$ \\ Universidad Católica San Pablo de Arequipa-Perú, Centro de Estudios Peruanos
}

\begin{abstract}
El presente artículo analiza las posibles causas que aseguraron la ausencia de bandolerismo en Arequipa en las postrimerías de la presencia hispánica en el Perú, utilizando las fuentes administrativas y criminales existentes. Teniendo como base los cambios en la estructura socio-económica que experimentó la región sur del Perú luego de las reformas borbónicas, se interpreta las causas que explican este fenómeno desde una perspectiva comparada con otras áreas del virreinato. Asimismo, se abordan las perspectivas historiográficas peruanas propuestas respecto al fenómeno del bandidaje —las que abundan en consideraciones de tipo economicista - proponiendo una re-interpretación de estos hechos delictivos desde un enfoque que privilegia el elemento cultural.
\end{abstract}

Palabras ClaVE: bandolerismo; reformas borbónicas; intendencia de Arequipa.

Cómo CitAR este artículo / Citation: Belan, César, "Las razones detrás (de la ausencia) del bandolerismo. El caso de la intendencia de Arequipa a fines del virreinato (1780-1824)", Revista de Indias, LXXX/278(Madrid,2020):251-274.https://doi.org/10.3989/revindias.2020.008.

\section{La INTENDENCia De AreQuipa. Algunos APUnTes SOCIO-ECONÓMicos}

El periodo final del dominio español en el Perú estará marcado por los profundos cambios operados en la sociedad y la economía a partir de las reformas

\footnotetext{
* Fuentes: Archivo Regional de Arequipa, ARAr. Archivo Municipal de Arequipa. AMA, Libros de Actas de Cabildo.

1 cbelan@ucsp.edu.pe, ORCID iD: https://orcid.org/0000-0002-1030-066X
} 
borbónicas. Un proyecto modernizador ${ }^{2}$ que tendrá como consecuencia, en tiempos de Carlos III, la reconfiguración territorial en los dominios americanos. En vista de esta nueva visión de la administración pública, y por la necesidad de un gobierno de estructura militar en regiones amenazadas por enemigos internos y externos, el 5 de agosto de 1783 se instauró la intendencia de Arequipa $^{3}$. Esta comprendía los partidos o subdivisiones de Arequipa, Camaná, Cailloma, Condesuyos, Moquegua, Arica y Tarapacá; cada una a cargo de un subdelegado. En ella, para el año 1793 habitaban algo más de 130000 personas, repartidas en «60 doctrinas, 2 ciudades, 2 villas y 80 pueblos anexos».

La ciudad de Arequipa constituía sede del gobierno y era conducida directamente por el intendente. Contaba para mediados del siglo XVIII con algo más de 20000 habitantes, cifra que llegaba a 40000 si se contaba a los pueblos circundantes a la urbe ${ }^{4}$. Esta localidad albergaba a una población mayoritariamente hispánica ${ }^{5}$.

En el ámbito económico, las reformas provocarían en Arequipa un impacto profundo, posibilitando el crecimiento de la región de manera acelerada y sostenida. Esto se debió fundamentalmente al desarrollo de la producción vitivinícola -impulsada fundamentalmente en los valles de la costa- y cuyos productos se destinaban al mercado de Potosí; y a la minería de las regiones de Tarapacá y Caylloma ${ }^{6}$. Nos referimos luego a un despegue económico que no decaería incluso en los turbulentos tiempos de inicios de la república 7 .

Este alentador escenario alentaría la migración en todos los estratos. La pequeña élite local fue reconfigurada a partir de la migración de montañeses y vascos. El conocimiento del comercio y las redes que los peninsulares mantenían en la administración colonial, generaron un auge inusitado en la productividad local, mediante la conjunción de estas habilidades y conexiones y la antigua propiedad de las familias de la región ${ }^{8}$.

2 Entendido este como un esfuerzo dirigido a «crear una maquinaria económica y financiera más eficiente, y en general para reimplantar integridad y respeto por la ley en todos los niveles de la administración». Fisher, 1968: i. Este proceso tuvo como base la aproximación cartesiana de la realidad según el paradigma ilustrado, es decir mediante «la adquisición de un conocimiento útil, una investigación racional [sobre esta]». Fisher, 2000: 161.

3 Fisher, 1981.

4 Zegarra, 1973: 13.

5 El estatus colonial - más conocido como «calidad»- era una compleja combinación de la identidad racial, ocupación, riqueza y predominantemente las prácticas culturales, es decir la asimilación de prácticas hispánicas o el mantenimiento de costumbres andinas o africanas. No debe, por tanto, asociarse con una mera realidad racial. McCaa, 1984.

${ }^{6}$ Buller, 2011. Brown, 2008.

7 Condori, 2012.

8 Malamud, 1982. 
Cuadro 1. Población de la Intendencia de Arequipa en 1793

\begin{tabular}{|l|c|c|c|c|c|c|c|}
\hline \multicolumn{1}{|c|}{ Partido } & Españoles & Indios & Mestizos & Castas & Esclavos & Religiosos & Total \\
\hline Arequipa $^{9}$ & 22687 & 5929 & 4908 & 2487 & 1225 & 485 & 37721 \\
\hline Camaná & 5105 & 1249 & 1021 & 1747 & 887 & 43 & 10052 \\
\hline Arica & 1585 & 12870 & 1977 & 985 & 1294 & 65 & 18776 \\
\hline Tarapacá & 509 & 5406 & 1200 & 528 & 253 & 27 & 7923 \\
\hline Moquegua & 5596 & 17272 & 2916 & 887 & 1526 & 82 & 28279 \\
\hline Condesuyos & 3663 & 12011 & 4358 & 34 & 44 & 35 & 20145 \\
\hline Cailloma & 212 & 11872 & 1417 & 335 & 29 & 40 & 13905 \\
\hline Total & 39357 & 66609 & 17797 & 7003 & 5258 & 777 & 136801 \\
\hline
\end{tabular}

Fuente: Unánue, 1793: 101-106.

El sector popular también se vino ampliando progresivamente con la migración de un buen número de mestizos o de indígenas altamente hispaniza$\operatorname{dos}^{10}$. La reconfiguración urbana a propósito de los sucesivos terremotos acaecidos en el s. XVII, y la necesidad de mano de obra para la reedificación de la ciudad también fue importante en este proceso de migración. Tiempo después, el declive del Cuzco como centro económico y político en los años de la revuelta de Túpac Amaru, la peste de 1720 y el bajo rendimiento agrícola de esos años, atraería también a la ciudad a muchos forasteros, ya mediados del siglo XVIII. El clérigo Ventura Travada y Córdova afirmaba al respecto: «se va extendiendo tanto el vecindario, mayormente de forasteros, que vienen atraídos de las vitalidades que hallan en la ciudad y su comercio, que en breve volverán a retirar más el rollo para dar más ensanche a la ciudad» ${ }^{11}$.

Este sector plebeyo solía ocuparse de diversas actividades artesanales y oficios entre los que podemos contar el de tendero, comerciante urbano, pulpero, notario, agrimensor, clérigo y pequeño agricultor de los campos que circundaban a la ciudad, y cuya producción satisfacía la demanda urbana de comestibles $^{12}$. Los sectores más deprimidos —en los que destacaban algunos indígenas, y los esclavos y pardos libres - se ocupaban de las labores más

9 Según los datos de Günter Vollmer, 23545 habitaban la ciudad y 13710 habitaban los suburbios alrededor de la ciudad. Buller, 2011: 94.

10 Barriga, 1941. Zamácola, 1958.

11 Travada y Córdova, 1958: 83.

12 Chambers, 2003: 70-71. Gutiérrez, 1992: 66-67. 
duras, actuando como servidumbre doméstica, peones agrícolas, albañiles, aprendices de oficios y mano de obra contratada. No obstante, los documentos notariales y de comercio atestiguan que las diferencias económicas entre los plebeyos eran mínimas, generándose así muchos vínculos familiares y clientelares entre los miembros de este grupo mayoritario ${ }^{13}$.

Una sociedad constantemente reconfigurada como la arequipeña posibilitaba entonces mayores chances de ascenso social por parte de esta gran clase plebeya. Esta situación, a lo que se suma la mayor ponderación de las hasta en ese momento «viles ocupaciones manuales» por la introducción de las ideas ilustradas, abrió un margen amplio de promoción ciudadana para artesanos y comerciantes $^{14}$.

\section{El Bandolerismo en el VirReinato del Perú de finales del S. XVIII}

La historiografía señala cómo en el dieciocho y el diecinueve se produjo un bandolerismo endémico en muchas regiones del virreinato del Perú y en otras regiones cercanas. Han quedado perennizados los nombres de famosos jefes de asaltantes - llamados «capitanes de bandidos» en la época- y sus correrías en las haciendas de los valles limeños de Carabayllo y Supe. Nombres como José Sifuentes, Fermín Antonio, Félix Lobatón, Pedro Nolasco Villar, Toribio Puente, Ignacio de Rojas, Manuel Bravo, Pedro León y Juan Pulido serán reiteradamente mencionados en la documentación judicial como causantes de los robos y las muertes en los caminos de Lima. Cometidos por grupos estables de veinte, treinta y hasta cuarenta hombres armados, estas bandas en las que abundaban los negros fugados y refugiados en palenques (cimarrones), serían el terror de los viajeros y la preocupación de las autoridades coloniales ${ }^{15}$. Pero no solo Lima era un lugar exclusivo de este tipo de crímenes.

Vivanco señala que la presencia de bandolerismo «no era exclusiva de la zona costeña de Lima lo prueba la presencia en Trujillo, hacia 1804, de una banda que estuvo conformada por esclavos de las haciendas Tomaval, San Idelfonso y Santa Elena» ${ }^{16}$. Lavallé y Chávez Marquina presentan similares impresiones al estudiar el bandolerismo en Trujillo ${ }^{17}$, además detallan las

13 Chambers, 2003.

14 Carlos III promulgó la honradez de todos los oficios mecánicos en una Real Cédula del 18 de marzo de 1784. Moral Roncal, 1996.

15 Flores Galindo, 2010. Andazabal, 2007. Espinosa Descalzo, 1999. Aguirre, 1990.

16 Vivanco, 1990: 50.

17 Chávez Marquina, 2015: 60. Lavallé, 1999: 182-183. 
correrías de famosos bandoleros como Juan Lazo. Manifiestan asimismo que las bandas de asaltantes no solo atacaban en los caminos, sino que se dedicaban al abigeato y al «pillaje a casas, tiendas y haciendas» ${ }^{18}$.

Este fenómeno se agudizaría luego de 1821 a causa de los débiles primeros gobiernos republicanos y la anomia generada por la coyuntura independentista, para alcanzar luego su máxima expresión en la anarquía militar que se produjo luego del proceso de emancipación; muchos de estos grupos criminales constituyeron incluso actores armados del incipiente «debate político» ${ }^{19}$. Al respecto Vargas Ugarte señaló:

La escasez, la apatía de la junta, la desmoralización del ejército y la marina, por la inercia y negligencia de los jefes y el atraso en el pago de los haberes y la desconfianza creciente en el gobierno y el congreso trajeron por consecuencia el recrudecimiento del bandolerismo ya desde el desembarco de San Martín en Paracas, por la libertad que dio a los negros esclavos que se incorporaran al ejército patriota y también por el fomento de las montoneras. Los caminos y aún las mismas calles de Lima se veían infestadas por partidas de malhechores a los cuales no alcanzaba a contener la fuerza pública. Era peligroso, así fuese de día, encaminarse al Callao sin armas y sin compañía, y fue necesario crear el Tribunal de la Acordada a fin de juzgar sumariamente a los malhechores y poner término a sus desmanes. Todo esto demuestra la confusión y el desorden existentes y también la falta de patriotismo de muchos individuos ${ }^{20}$.

Incluso, en algunos de los testimonios judiciales consultados se hace eco del aquel sombrío panorama en los albores de la república; afirmaciones en los vecinos arequipeños dejan constancia de la conciencia de peligrosidad que mantenían con respecto a los caminos que iban a la capital. Así pues, Juan Baldivia en una disputa con el alcalde de Siguas, replicará a la autoridad a manera de injuria: «baia U. a las pampas de Lima á acompañarse con los fasinerosos a matar» ${ }^{21}$.

Por otro lado, las bandas de asaltantes no eran un fenómeno exclusivo de la costa. Stavig, al estudiar los crímenes ocurridos en regiones serranas como Canas, Canchis y Quispicanchis en el Cuzco, da cuenta de pandillas estables

18 Chávez Marquina, 2015: 61.

19 Walker, 1990.

20 Vargas Ugarte, 1966: 251.

21 Archivo Regional de Arequipa, ARAr, Intendencia, Criminal, legajo 91, exp. (24XII-1815) «Causa criminal seguida por el Alcalde de Siguas D. José Antonio Martínez del Campo contra Casimiro Bolaños, su muger Januaria Baldivia, y Juan Baldivia su hermano; por perdimiento de respeto, y atropellamiento a la Real justicia, la noche del 24 de diciembre: y remitida esta causa al Sr. Governador Intendente de esta Provincia», fjs. 3 . 
de ladrones — muchas veces parientes y amigos - que se dedicaban al robo habitual de ganado entre las comunidades de la zona ${ }^{22}$.

Ya remitiéndonos a otros lugares del continente, podemos citar al trabajo de Aspell sobre la delincuencia en Tucumán en el período que nos atañe. La autora, entre otros hechos, refiere las hazañas del famoso cuatrero y bandolero Juan Bautista Guayanes, «habilísimo en el manejo del facón, [...quien] desde pequeño andaba huido de su padre y de las justicias robando continuamente haciendas de campo y mujeres», un ejemplo tan solo de una población «que vivía con poco temor de Dios ni respeto por la real justicia» ${ }^{23}$. Por su parte Fradkin señala que las gavillas de salteadores eran un problema serio y endémico desde 1770 en Buenos Aires, Santa Fe, Entre Ríos y la Banda Oriental, y que se agrava seriamente desde 1810 hasta el periodo de la guerra civil. Al respecto señala:

Aunque no estamos en condiciones todavía de trazar un cuadro preciso del bandolerismo a fines del período colonial en el conjunto del área rioplatense las evidencias disponibles sugieren que las gavillas de salteadores eran frecuentes, que muchas veces se reclutaban entre desertores y perseguidos de la justicia y que su patrón de actividades incluía desde el contrabando de cueros y ganados al Brasil hasta el saqueo de pulperías y poblados y que no era infrecuente el "robo" de mujeres ${ }^{24}$.

Este cuadro generalizado de bandolerismo en Latinoamérica de mediados del s. XVIII e inicios del s. XIX, podría alentarnos a pensar que en Arequipa - un polo de desarrollo económico en la época - también este tipo de hechos delictivos eran frecuentes. Sin embargo, el caso de la «ciudad blanca» parece ser la excepción. Adentrémonos más en este hecho.

Luego de revisar exhaustivamente las causas criminales desde $1750^{25}$, nos percatamos que no existe constancia de la existencia de bandas de asaltantes que acechaban a los transeúntes de los caminos de la intendencia. A pesar de haberse promovido un buen número de procesos por homicidios perpetrados en los caminos, tal como se señalará con detalle más adelante, ninguno de estos crímenes revestirá las características de un ataque en banda. Asimismo, el carácter pacífico de la región es patente en las declaracio-

22 Stavig, 1985, 1990.

23 Aspell, 2008: 213-214.

24 Fradkin, 2005: 9.

25 Para la elaboración del presente trabajo se analizaron el íntegro — alrededor de 400 de las causas criminales y administrativas que obran en el Archivo Regional de Arequipa (ARAr) en el período que va desde 1750 a 1824, catalogados en los legajos 26 (Corregimiento/Causas Criminales), 85-97 (Intendencia/Causas criminales) y 107 (Intendencia/Causas administrativas). 
nes de las autoridades y de los viajeros. Así pues, Antonio Álvarez y Jiménez —intendente desde 1785 hasta 1796 - refiere continuamente en su relación de visita no encontrar causas judiciales pendientes y aun reos, en los pueblos visitados «ya por la tranquilidad y buena armonía en que todos se han encontrado y se mantienen» ${ }^{26}$. De igual forma, su sucesor, Bartolomé María de Salamanca (1796-1811), resalta en su relación de gobierno «la religiosidad y sencillez de sus moradores», señalando que «fue muy raro el homicidio perpetrado en los grandes despoblados de tan dilatada provincia» ${ }^{27}$. Casi contemporáneamente, el viajero alemán Tadeo Haenke (1830) al visitar la ciudad en la última década del S. XVIII sostendrá que «los delitos dominantes de la plebe no son de consideración, por ser toda aquella gente apacible y de buena inclinación ${ }^{28}$.

Por otra parte, las alusiones concretas a bandoleros o salteadores son mínimas en los documentos administrativos. Así pues, al referirse al pueblo de Yanahuara, el Gobernador Intendente Álvarez y Jiménez hace mención a la peligrosidad del paraje hoy conocido como Pampa de los Cañaguas, tránsito obligado hacia el Partido de Caylloma y la Ciudad del Cuzco, por «la dolorosa experiencia de los asesinatos y descaminos que en aquel despoblado se han executado siempre» ${ }^{29}$. Esto se hará mención en el Acuerdo de Cabildo celebrado el 25 de agosto de 1777, que, remitiéndose años atrás, en tiempo del corregidor Juan Pacheco, señalaba:

...ciendo constante a Vs. y especialmente a los SS jueces los continuos descaminos y muertes que se hacían en las entradas de los caminos dela sierra y otras partes a esta ciudad la pusieron en su lamentable estado, de modo que a esta nos se podía entrar mantenimientos ni menos salir los comerciantes temiendo se hiciera lo propio con ellos, por lo que dichos jueces se vieron en precisión de dar todas las providencias necesarias y aún haber salido en persona para aprehender a los delincuentes y expurgar esta provincia de ellos e imponerles las penas correspondientes que queden escarmentados y sirviese a otros de ejemplo, celaron los caminos y aprehendieron a algunos, aun con los efectos descaminados ${ }^{30}$.

Sin embargo, como ya se ha dicho, al remitirnos a las causas criminales encontramos que los asesinatos y robos perpetrados en el camino que iba de Arequipa a Caylloma (y en especial en la citada zona de Pampa Cañaguas)

\footnotetext{
26 Barriga, 1941: 138.

27 Fisher, 1968: 37; 39.

28 Haenke, 1901: 189.

29 Barriga, 1941: 255.

30 Archivo Municipal de Arequipa, AMA, Libros de Acuerdo de Cabildo, legajo. 24, exp. (25-VIII-1777) «Sobre la Real Carcel».
} 
estas se produjeron como un «crimen de oportunidad» ${ }^{31}$, o fueron ejecutados por los acompañantes de los comerciantes o viajeros aprovechando su relación de confianza, sin que mediaran grupos de facinerosos organizados.

Como ejemplo de un asalto en caminos como consecuencia de un «crimen de oportunidad» encontramos al caso de Esteban Carrillo. Indio tributario de Lluta, sería acusado por la familia de su mujer de haber asesinado a su cónyuge. Luego de ser detenido y fugar de la cárcel de su pueblo, sobreviviría haciendo pequeños hurtos de animales a propietarios y viajeros desprevenidos, en el camino de Yuta a Guanca. Finalmente se enrolaría «bajo las armas del Rey» buscando así que su delito sea indultado 32 .

En esa misma línea, podemos citar los asesinatos del comerciante español Thomas de Soto en 1795, y de don Antonio Raberto, encargado de «azentista» general de azogues de Huancavelica, en 1800.

El primero de estos crímenes acaeció la madrugada del 09 de junio de 1795 en el camino que une los pueblos de Condoroma y Callalli, en el valle del Colca. Por esta ruta que llevaba hacia Cuzco se dirigía el arriero Thomas de Soto, procedente de la península y vecino del Cuzco. Iba en compañía de Dionisio Cáceres, indio natural del valle, y el hijo menor de edad de este último. En el trayecto de De Soto realizaría actividades comerciales propias de su oficio, extendiendo y cobrando pagarés a diversos residentes del valle. Llevaba además una carga de «especies de Castilla» para el comercio; una serie de prendas empeñadas por sus deudores, tal como joyas y espuelas de plata; y al mismo tiempo una considerable cantidad de «piñas» del mismo metal y dinero en metálico. Tal como lo confesará el propio Cáceres posteriormente, De Soto y su acompañante entrarían en disputa por la cantidad de dinero que debía recibir el ayudante por sus servicios; este hecho finalmente empujaría al empleado a asesinarlo propinándole doce puñaladas. Luego del asesinato, Cáceres enterraría superficialmente el cadáver a la vera el camino, lo que no pasaría desapercibido por los indios residentes en el lugar, quienes, descubriendo el hecho, capturaron al malhechor y lo pusieron a disposición de sus caciques y de los funcionarios de la Corona. El hijo de Cáceres escaparía cuando trataba de deshacerse de los bienes robados, y se asilaría en un

31 Según la teoría criminológica de Marcus Felson, el crimen de oportunidad es aquel en el que el delincuente actúa — más allá del ejercicio de una actividad cotidiana de subsistenciateniendo en cuenta la «oportunidad» del delito, es decir que, apelando a la racionalidad delictiva, encuentra una circunstancia delictiva un provecho económico mucho mayor a las posibilidades de riesgo de la acción. A esto se suma las precariedades y necesidades del sujeto del delito que impulsan a «hacer uso de esa oportunidad». Miró Linares y Agustina Sanllehí, 2015.

32 Archivo Regional de Arequipa, ARAr, Intendencia, Criminal, legajo 85, exp. (1789) «De oficio contra Esteban Carrillo por robos, fuga de cárcel y uxoricidio». 
convento de donde fugaría definitivamente. Dionisio Cáceres, finalmente, sería condenado tres años después al presidio del Callao, lugar al que no lograría llegar por morir en la Real Cárcel de la ciudad antes de ser trasladado ${ }^{33}$.

El segundo homicidio, acaecido no muy lejos del asesinato de De Soto, ocurrió en la citada Pampa de Cañaguas, en la ruta que iba hacia el Cuzco. Finalizaba el mes de septiembre del año 1800, y don Antonio Raberto, «encargado del azentista general de azogues de Guancavelica»s se dirigía con su carga de azogues a las minas cercanas. Lo acompañaba Margarita Munari, viuda y arriera de Huancavelica, quien fletaría las mulas a Raberto y proporcionaría un grupo de hombres para el servicio del azoguero. La relación entre Raberto y sus acompañantes venía enturbiándose, ya que este no quería compartir la ganancia producida por la merma y la venta ilegal de los azogues. El detonante se produjo cuando, ya en Arequipa, Raberto prefirió la compañía de una lugareña a la de Munari, quien a decir de sus empleados era la amante del «azentista». Por instigación de Munari y en combinación con el secretario de la víctima, Mariano Salvatierra, se resolvió asesinar a Raberto en la madrugada del día veintiséis, para lo cual tomaron chicha a fin de darse ánimos. El hijo de Margarita Munari llamado José Garabai, y dos de sus peones: Gregorio Mosqueira y Bartolomé Flores consumarían el hecho. Raberto sería arrojado de su cabalgadura a pedradas y jalones cuando ya caía el sol, acuchillándole Mosqueira y rematándole Garibai con el propio sable de la víctima. Los asesinos se apresuraron a enterrar el cuerpo al borde de la ruta, y partieron a Arequipa a dar cuenta de la «misteriosa desaparición de su patrón». Antes esconderían la carga sustraída enterrándola en el piso de un tambo. Sin embargo, la condición de forasteros que ostentaban los criminales levantó sospechas entre los residentes - especialmente los indios lugareños, tal como ocurrió con Dionisio Cáceres años antes-; estos encontraron el cuerpo y detuvieron a los delincuentes cuando buscaban escapar. No pasaría mucho tiempo sin que los reos cambiaran sus declaraciones iniciales y comenzaran a delatarse mutuamente. Mosqueira y Flores serían condenados a la pena capital, pero morirían en cárcel antes de ejecutarse su pena. Garabai, por su condición de menor de edad, sería condenado a servir en el Callao, pero escaparía antes de ser trasladado. Por su parte, Margarita Munari sería remitida al obraje de Acobamba en Huancavelica ${ }^{34}$.

33 Archivo Regional de Arequipa, ARAr, Intendencia, Criminal, legajo 85. exp. (10-VI1796) «Dionisio Cáceres por el homicidio de Thomas de Soto».

34 Archivo Regional de Arequipa, ARAr, Intendencia, Criminal, legajo 87. exp. (26-IX1800) «Por el homicidio de don Antonio Raberto, encargado de azentista general de azogues de Huancavelica». 
Queda patente luego, que los dos crímenes antes narrados se perpetraron a consecuencia del abuso en la relación de confianza que existía entre la víctima y el (o los) agresores. Hablamos pues de viajeros (comerciantes y funcionarios) que transitaban por los caminos reales en compañía de ayudantes o sirvientes y, quienes luego de disputar con sus patrones - normalmente por asuntos de índole económico- proyectarían y ejecutarían el asesinato de su empleador y el robo de sus pertenencias. Así pues, la existencia de una banda criminal en ambos casos queda descartada.

Otro punto de peligro específico de los caminantes y viajeros mencionado por las autoridades será la quebrada del Jagüey, en el camino de Arequipa a Puno y al Valle de Tambo. En este lugar el intendente Álvarez y Jiménez mandó construir un tambo para que «no se cometan los excesos que hasta el presente se han visto, por las muertes que en aquella quebrada se han hecho, y también para remediar los muchos robos que se hacen en la Ciudad, que por allí salen a varias partes» ${ }^{35}$.

No obstante, sobre ese lugar en particular mantenemos constancia de un solo asalto sangriento; homicidio que, por otro lado, nunca fue del todo acreditado por no haberse encontrado el «cuerpo del delito» y que, por otra parte, tampoco apunta a la existencia de una banda de salteadores. Se trata del largo proceso seguido a Andrés Zegarra, mulato esclavo de don Fernando Vilago, acusado de haber asesinado a Ramón Mantilla en el que camino que iba de Arequipa al valle de Tambo. Según la acusación fiscal, Zegarra habría acuchillado a Mantilla causándole la muerte. Según el esclavo, la supuesta muerte de Mantilla se produjo al intentar proteger la carga de guiñapo que transportaba, luego que este individuo intentase robarlo. Finalmente, el esclavo sería absuelto del homicidio al no haberse nunca podido acreditar la muerte de Mantilla y por existir testigos que indicaban que el presunto asesinado seguía vivo ${ }^{36}$.

Si bien el principal móvil del asesinato en los caminos apuntaba a ocultar un robo, no todos los homicidios cometidos estarán relacionados únicamente con el lucro. Lo subrepticio de ese espacio también era adecuado para ejecutar crímenes sentimentales en los que se buscara acabar con un ocasional rival amoroso o esposa infiel. Ya el asesinato del Antonio Raberto, «azentista» de azogues de Huancavelica, tendría implicancias sentimentales. Como se ha señalado, Margarita Munari, una de las mayores instigadoras del asesinato, maquinaría el crimen a causa de la infidelidad del «azentista».

\footnotetext{
35 Barriga, 1948: 297.

36 Archivo Regional de Arequipa, ARAr, Intendencia, Criminal, legajo 85, exp. (16-VI1785) «De oficio contra Andrés Zegarra, mulato esclavo de don Fernando Vilago, por el homicidio de Ramón Mantilla».
} 


\section{¿BANDOLERISMO SOCIAL, ECONÓMICO O POLÍTICO? NUEVAS PERSPECTIVAS}

Los estudios sobre bandolerismo sientan sus bases sobre los -a estas alturas ya clásicos - trabajos de Fernand Braudel ${ }^{37}$ y Eric Hobsbawn ${ }^{38}$. Este último postulará en 1974 su famosísima tesis sobre el bandolero social: «un tipo excepcional de salteador rural, solidario con los campesinos frente a sus opresores, admirado y apoyado por la comunidad, empujado al margen de la ley por una injusticia o un hecho que las costumbres locales no consideran verdadero delito, cuya fama es que "corrige los abusos" [de los potentados] ${ }^{39}$. Durante las últimas tres décadas las tesis de Hobsbawn han venido siendo discutidas, compartidas y criticadas. En líneas generales $-\mathrm{y}$ sin desmerecer el trabajo pionero de este estudioso británico - el debate se inclina a cuestionar sus fuentes y conclusiones iniciales, remarcándose que en sus trabajos no se distinguió convenientemente entre el mito del bandido y su figura real. Se sugerirá luego que

el ladrón noble tuvo sus raíces en el interés que tenían los historiadores marxistas por la existencia de la figura de Robin Hood. Es lo que explica que la elaboración del ladrón noble [bandido social] a partir de las hazañas y leyendas de Robin Hood parece más una intencionalidad ideológica que una realidad en sít ${ }^{40}$.

Estudiosos como Billy J. Chandler, James Clarke Holt, David Montgomery Hart y José Gonzalez Alcantud sostendrán esta postura.

Una nueva e interesante interpretación a este fenómeno será la de Xavier Torres i Sans ${ }^{41}$. Respondiendo a la opinión de Braudel, que planteaba el carácter de «subsistencia» del bandolerismo catalán por considerarlo «el resultado de la carestía y la presión demográfica ${ }^{42}$, afirmará, apartándose de las consideraciones más tradicionales, que la miseria y el aumento poblacional no pueden considerarse como suficientes para dar luz sobre este hecho. Al analizar el bandolerismo en Cataluña, Sicilia, Abruzzo, Córcega y Nápoles encontrará que los bandoleros no pertenecían a la clase menesterosa, sino que, por contrario provenían de sectores medios o privilegiados. Así pues, concluirá Torres i Sans, la actividad bandolera estaría más ligada a la crisis política

37 Braudel, 1976 [1949].

38 Hobsbawm, 1974 [1959]; 1976 [1969].

39 Chumbita, 1999: 84.

40 Moreno Sandoval, 2012: 278. Para un desarrollo exhaustivo del debate historiográfico sobre bandolerismo social véase el segundo capítulo de este trabajo.

41 Torres i Sans, 1999; 2003.

42 Torres i Sans, 2003: 1. 
surgida entre los señores locales, sus «guerras privadas», y el control abusivo con el que sometían a vasallos poco fieles.

Lo sostenido por Torres i Sans coincide en gran parte con los planteamientos de Sánchez y Meertens, quienes en su análisis sobre la violencia y el bandolerismo en Colombia ampliaron la tipología hasta en ese entonces vigente, postulando la existencia del bandolero político: malhechores que fungían como agentes de caudillos políticos y potentados locales dirigidos a coaccionar a las masas campesinas o urbanas. Confiados en el terror que infundían y en el apoyo de los más poderosos, en ellos «la subordinación política no es aquí un mero accidente en la carrera del bandolero, sino el elemento que motiva y define, en primera instancia sus actuaciones y sus blancos $\rangle^{43}$. Lamentablemente las investigaciones de Torres i Sans y de Sánchez y Meertens no hicieron mucho eco en los estudios que, sobre el bandolerismo, se han desarrollado en el Perú.

Entre las más tempranas críticas a Hobsbawn destaca la de Anton Blok ${ }^{44}$, que ha influenciado notablemente los trabajos que sobre bandolerismo se han hecho en Latinoamérica ${ }^{45}$. En ellos se cuestionan los vínculos de solidaridad que los bandidos sociales pudieran haber mantenido con el campesinado o los pobres, buscando solo participar egoístamente de la distribución de beneficios. Así pues, cangaçeiros, gauchos y demás bandidos americanos estarían más fielmente catalogados como delincuentes comunes, quienes, aprovechando la ocasión, no solo atacarían y extorsionarían a los más pobres, sino que además no perderían la oportunidad de servir a los intereses de los ricos y poderosos. Este tipo de bandido para Blok, sin embargo, permanecía constituyendo un producto de los factores económicos.

Lo económico en el bandolerismo está presente tanto en sus motivaciones de sobrevivencia como en la conformación del estatus y en sus fines [...] Es un fenómeno social a través del cual ciertos sectores de la clase dominada expresan descontento y reivindicación concreta contra la situación social ${ }^{46}$.

Es en esta línea, la del Bandido económico, en la que se inscribe la mayor parte de la historiografía peruana que se ha abocado al tema del abigeato, bandolerismo y delincuencia. Esquemas en los que básicamente se relacionan las conductas criminales con prácticas - exitosas, fracasadas o aparentes- de subversión a los patrones económicos de dominación.

\footnotetext{
43 Sánchez y Meertens, 1982: 26.

44 Blok, 1972.

45 Slatta, 1987

46 Vivanco, 1990: 29, 35.
} 
Así pues, Aguirre, que, partiendo bajo estos presupuestos ${ }^{47}$, estudia el cimarronaje y el bandolerismo en Lima de fines del s. XVIII, llega a las conclusiones siguientes:

El cimarronaje [constituyó] una forma de resistencia legítima y además eficaz contra la dominación [...] una expresión clara de la capacidad de los esclavos para re-crear las nociones de "justicia" dominantes, convirtiendo así lo que era una prédica vacía e hipócrita de parte de las clases dominantes, en una herramienta de confrontación y conquista de sus propias reivindicaciones. [Mientras que los bandoleros...] eran solo una expresión de malestar permanente al interior de una sociedad injusta $[. .$.$] carecían del consenso aprobatorio de sus iguales y con frecuen-$ cia sus prácticas perjudicaban a los sectores populares ${ }^{48}$.

Finalmente, según la historiografía peruana, las bandas de africanos y mestizos que sembraban el terror los caminos de Lima y el norte del país a cualquier transeúnte más allá de su riqueza o etnia, se inscribirían en el tipo del bandolero económico ${ }^{49}$.

Así también, según estas premisas, las condiciones económicas arequipeñas también podrían haber dado a luz brotes de bandolerismo en los que las clases oprimidas volcaran su furor revolucionario en prácticas de «cuestionamiento» del sistema imperante; algo que finalmente no ocurrió en la realidad. Así pues, estos enfoques adolecerían de lo que Fradkin señaló en su análisis historiográfico sobre el bandolerismo: «a fuerza de simplificar extremadamente la discusión puede decirse que se ha pecado de tentación taxonómica» ${ }^{50}$.

La casi nula ocurrencia de bandolerismo en Arequipa, por otro lado, sugiere un panorama nuevo y plantea, a la vez, la necesidad de nuevas interpretaciones. Hablamos de aproximaciones que incorporen nuevas variables para entender estos hechos, las que maticen el enfoque económico, predominante en la historiografía nacional. Se hace preciso pues relativizar una única respuesta económica que tendería a reducir la complejidad de los hechos, como ya la hubiera propuesto Torres i Sans para el caso catalán que le ocupa:

De hecho, en ocasiones, esta [el bandolerismo] podía ser la salida más difícil o impracticable, pues no todos los desharrapados podían hacerse con el bagaje imprescindible de los auténticos bandoleros [...] lo que debiera explicarse es más

47 «Después de todo durante la mayor parte de nuestra historia el único recurso al alcance de las clases oprimidas para intentar participar de mejor manera en el reparto de los excedentes sociales ha sido la transgresión de la ley y la comisión de delitos». Aguirre, 1990: 143.

48 Aguirre, 1990: 155, 177.

49 Caso particular será el de Walker, 1990, quién estudiará el Bandolerismo político relacionado con la anarquía militar que siguió a la Independencia.

50 Fradkin, 2005: 6. 
bien por qué razón el descontento o la desesperación de los "hijos de la miseria" se manifestó o desahogó en la Cataluña de los siglos XVI y XVII por la vía de un tipo específico y sostenido de violencia o bandolerismo; en lugar, por ejemplo, del vagabundaje de masas, o más simplemente todavía, la emigración, tal como sucediera en muchas otras latitudes europeas durante el mismo periodo [...] Así pues la miseria y la sobrepoblación no lo explican todo, pues el bandolerismo catalán de la edad moderna se alimentaba de los ricos y poderosos - y de sus disputas particulares - antes que de los pobres y oprimidos —y de sus dificultades ${ }^{51}$.

\section{UNA APROXIMACIÓN CULTURALISTA}

En el caso arequipeño, entre otras cosas, sorprende la baja incidencia de crímenes de afroperuanos en la región, ya que la presencia negra en la intendencia no era nada despreciable, encontrándose un gran contingente africano en las haciendas de la costa arequipeña, y en Moquegua o Arica: el $66 \%$ de los esclavos del total de la intendencia habitaban el valle de Vítor y el 29,5\% el del río Tambo (por el contrario, en la ciudad el número de esclavos era considerablemente menor ${ }^{52}$ ). Asimismo, resalta que el número de negros horros o libertos era muy escaso en la intendencia, siendo así que la existencia de este grupo étnico era muy gravosa por su estatus predominantemente esclavo.

De igual forma, las actividades agrícolas en los valles generaron incremento de una población flotante, siendo que «el trabajo asalariado estacional había superado a la esclavitud en las haciendas $\rangle^{53}$. Evidentemente esta población desarraigada era más susceptible a cometer actos delictuosos, y por ende a generar violencia, sin embargo, esto no se tradujo en la realidad.

Por otro lado, a pesar del auge vitivinícola de fines del s. XVIII, el caudal de los vecinos de la ciudad y de la intendencia en general no era significativo, dando lugar únicamente a una clase adinerada de segundo nivel. Asimismo, según el párroco de Cayma, Juan Domingo Zamácola ${ }^{54}$ y el propio gobernador intendente Álvarez y Jiménez ${ }^{55}$, en la ciudad no faltaban tampoco los comunes

51 Torres i Sans, 2002: 4 y s.

52 A finales del XVIII se cuentan entre 5268 según Flores Galindo, 2010 y 2164 para Chambers, 2003. En cualquier caso, estas cifras no excedían al $10 \%$ del total de la población urbana, encontrándose muy por debajo de los 29763 que habitaban Lima, donde se concentraba el $73,7 \%$ de la población negra.

53 Brown, 2008: 48.

54 «[...] en una palabra, no se viera por las calles de Arequipa y sus contornos tanto número de hombres y mujeres entregados a una afrentosa mendicidad». Zamácola, 1958: 47.

55 «[...] no se verían tanto número de hombres y mujeres entregados a una afrentosa mendicidad». Barriga, 1941: 286. 
cuadros de miseria que eran propios de las ciudades indianas, aunque no de la manera escandalosa de Lima y México ${ }^{56}$. La pobreza de los pobladores, evidenciada fundamentalmente en escasez de trigo, fue acentuándose en el desalentador contexto de la guerra contra la Gran Bretaña ${ }^{57}$.

Así pues, frente al contexto de inestabilidad política y de realidades económicas no del todo favorables, una pregunta resulta obvia: ¿por qué no hubo brotes significativos de bandolerismo en el ámbito sur peruano, como si ocurrieron en otros lugares del virreinato y de Latinoamérica? La respuesta a este fenómeno puede orientarse más al ámbito cultural y, en específico, al de los patrones de asimilación a los valores de la comunidad.

Arequipa, en el s. XVIII e inicios del XIX, destaca por una constante reconfiguración de la población debido a las constantes migraciones producidas desde el s. XVII, y por una tendencia hacia la isonomía de una gran clase plebeya dedicada a diversas profesiones u oficios o que poseía o cultivaba una pequeña parcela. Un sector social que destacaba por un ingreso medio y en el que no se registraban notables diferencias — culturales, étnicas, económicas - entre sus miembros.

Estas condiciones (la flexibilidad propia de una sociedad reciente y constantemente reconfigurada y su tendencia isonómica) se traducían en mayores posibilidades de ascenso social, ya que criterios de ordenación social como la etnia, raza o riqueza eran ambiguos o muy parejos. Esto, sumado al hecho de que - por la irrupción de las ideas ilustradas - el Monarca elevó la condición de las hasta en ese momento «viles ocupaciones manuales» en oficios honrados, abrió un margen amplio de promoción ciudadana para artesanos y comerciantes ${ }^{58}$. Por otro lado, gracias a las propicias circunstancias económicas de la ciudad, estos sectores podían prosperar económicamente, como efectivamente lo hacían; sin embargo, la holgura monetaria no siempre se condecía con el ascenso social, cuyo reconocimiento muchas veces pasaba por diferentes cauces que el económico.

Es así que el ascenso social estaba profundamente relacionado por una asimilación plena de los principios y valores de la comunidad, algo que sería causa de la fuerte aculturación indígena, la vehemente adopción de los valores hispánicos ${ }^{59}$ y el vehemente realismo de los vecinos en las postrimerías

56 Flores Galindo, 2010: 196-197.

57 Fisher, 1968: 41.

58 Moral Roncal, 1996.

59 La hispanización de todos los sectores de la ciudad — en especial el indígena- ha quedado de manifiesto gracias a los trabajos de Chambers, 2003 y Condori 2010. La adscripción de los valores hispánicos por parte del sector indígena — catalogado así de ladino- 
del dominio español ${ }^{60}$. Así pues, se debía emular al modelo del «caballero cristiano» para obtener mayor destaque en la comunidad. Esta preocupación por la reproducción de los valores del antiguo régimen $-\mathrm{y}$ en especial del honor- aparece constantemente en las relaciones que poseemos sobre la ciudad. Una en especial, la relatada por Bernardino Fernández de Velasco — el Duque de Frías - en su «Deleite de la discreción y la fácil escuela de la agudeza», ilustra este hecho:

En Arequipa, ciudad de gran probeza en el Perú, y de tal vanidad de sus Vecinos, que por ella se dice aquel Proverbio: De dones, pendones y muchachos sin calzones. Sucedió que llegando á apearse en la posada cierto religioso grave, vió un mozuelo hecho andrajos, díxole: - Há mancebo, tenme este estrivo. Respondióle enfurecido: - Há Padre, sabe que habla con N. de tal, y de tal?, arrojándole millones de apellidos; á lo que dijo el religioso: - Pues señor don fulano de tal, y tal, y tal, vuestra merced vístase como se llame o llámese como se vista ${ }^{61}$.

Por otro lado, sociedades - como las de Lima y Cuzco- que no fueron sometidas a cambios demográficos profundos y cuyas élites eran más estables y permanecían más consolidadas, proporcionarían un marco de despliegue social mucho más limitado, ciñéndose únicamente a representar dos tipos de individuos: los «integrados», como los indios naturales en el caso de las comunidades del Cuzco y los grupos criollos y peninsulares en el caso de Lima; y los «marginados», aquellos que por saberse fuera de la órbita de los valores y representaciones de la sociedad en que vivían, no tendrían mayor reparo en atacar a su comunidad por no estar integrada a ella. Hablaríamos pues de los negros y mestizos implicados en bandolerismo en Lima y en las haciendas norteñas, y los indios forasteros en las comunidades indígenas del Cuzco, quienes se dedicaban usualmente al abigeato ${ }^{62}$.

Así como Casey ${ }^{63}$ y Muir ${ }^{64}$ advirtieran sobre una relación entre estructuras estatales débiles y bandolerismo, observamos que - más que estructuras estatales - la solidez de las estructuras sociales, expresadas como vínculos

se hace patente en las fuentes documentales de la época: Barriga, 1941. Zamácola, 1958. Carrión, 1983.

60 Arequipa sería uno de los últimos rincones en Latinoamérica en aceptar la ruptura del vínculo colonial. Inclusive después de que el virrey La Serna hubiera acordado la independencia del Perú mediante la Capitulación de Ayacucho, don Pío Tristán — criollo y vecino arequipeño - se opondría a tal resolución autoproclamándose virrey y organizando una milicia irregular que pronto sería reducida por los ejércitos patriotas.

61 Duque de Frías, 1743: 84. Carrión, 1983: 376.

62 Stavig, 1985, 1990.

63 Casey, 1979.

64 Muir, 1998. 
orgánicos de comunidad, conformarían una variable importante para la génesis del bandolerismo. Se establece así una correspondencia entre crímenes graves y desarraigo, tal como ya se observa en otras investigaciones y que hemos podido advertir en la propia Arequipa. Rara vez pues, un miembro de una comunidad - asimilado a ella no solo por habitar más o menos permanentemente en una locación, sino por compartir una tradición y una mentalidad colectiva que se expresa en espíritu de cuerpo e intereses imaginados como compartidos - rechaza procurar grandes trastornos a su entorno por un crimen que le acarreará una ganancia económica. Si los vecinos realizan estas conductas, estas serán cometidas más bien por influjo del alcohol, en el ardor de una disputa, o en circunstancias donde la razón se ve alterada, disminuida o empujada a una decisión poco meditada. En suma, se cumple aquel viejo adagio castellano que dice: «El buen jitano respeta su barrio», conforme lo cita Terreros y Pando en su diccionario, comentando además «que denota, que es mayor inhumanidad hacer mal á los mas cercanos y amigos» ${ }^{65}$.

Es en esa línea que Stavig describe como «los delincuentes indios [forasteros] eran traídos ante la justicia por otros indios [naturales de Canas, Canchis y Quispicanchis] que a menudo los veían como desadaptados, flojos y a veces peligrosos» ${ }^{66}$, discriminándoseles al atribuirles así las características inciviles que pesaban como prejuicios sobre la colectividad indígena ${ }^{67}$. El valor mismo de la supervivencia social - que estaba garantizado por la reproducción de las pautas de policía que permitirían la subsistencia - suponía la discriminación de aquellos comportamientos que pusieran en riesgo la estabilidad del grupo, y por tanto todos los sectores sociales echaban mano de estos «prejuicios» para manifestar su desprecio a otro. Luego, los indígenas asimilaron estos criterios de discriminación y «fortalecieron al sistema colonial al darle importancia cultural al control de la delincuencia» ${ }^{68}$.

El nacimiento, éxito o fracaso de las pandillas de malhechores estaría entonces marcada mayormente por las relaciones sociales complejas, y sobre todo por la solidez de las instituciones que producen y sostienen eficaces «códigos de ciudadanía». El binomio dominante/dominado (que comúnmente se ha manejado en la historiografía peruana) cede así lugar por un complejo entramado humano, en el que las sociedades más integradas serían importantes para explicar la ausencia del fenómeno, además del elemento económico. Las comunidades indígenas serán un buen ejemplo de esto. De ellas tratará

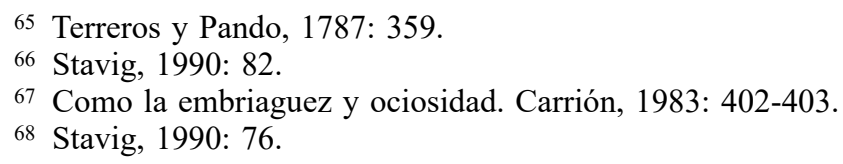


Langer, estudiando la región de Chuquisaca en el período que nos ocupa. Según el autor «el bandolerismo no se propagó en zonas donde las comunidades indígenas eran suficientemente fuertes y cohesionadas para enfrentar presiones externas» ${ }^{69}$.

Sin descartar las razones económicas imbricadas, nos orientamos pues a sugerir que el estallido de la delincuencia organizada corresponderá más a patrones de asimilación social de los miembros de una comunidad, en tanto los valores y anhelos del grupo humano son sostenidos y reproducidos por quienes los componen. En aquellas comunidades cohesionadas no solo no se generará bandolerismo, sino que el que se presente por agentes externos - como el provocado por forasteros desintegrados del imaginario local—será eficazmente censurado, perseguido y anulado. De otro lado, aquellas sociedades que por su rigidez estructural impidan la participación (incluso imaginada) de un sector determinado en el cuerpo social y de sus valores, impulsarán a que dichos miembros marginados ataquen abiertamente a su entorno mediante prácticas como el bandolerismo. Hacemos referencia, pues, al amplio desarrollo teórico que relaciona al delito con las estructuras culturales de cohesión social y los valores comunes de una comunidad ${ }^{70}$, conceptos que tienen como precursor al funcionalismo de Durkheim ${ }^{71}$.

Al respecto, la corriente «subalternista» inaugurada por Ranajit Guha se aproxima a esta interpretación señalando que «el orden social deriva su estabilidad de un acuerdo firme y tradicional, si bien tácito, entre gobernantes y gobernados, sobre un código mutuamente aceptable de dominación y subordinación ${ }^{72}$. Luego, las crisis culturales que desvían los significados de estos «códigos de subordinación» serán los que generarán la violencia. En la línea de lo planteado por este destacado teórico, entendemos a las relaciones sociales como códigos de convivencia aceptados y/o producidos por la comunidad. Estos acuerdos tácitos entre los diferentes estratos de la sociedad que aseguran la supervivencia y desarrollo de un grupo — «códigos de ciudadanía», más que de subordinación - harán referencia al entramado de valores, representaciones e ideales de una comunidad determinada más allá de la desigualdad de roles que ocupen sus miembros ${ }^{73}$.

69 Langer, 1990: 21.

70 Fernández Riquelme, 2017.

71 Durkheim, 1987, 1999.

72 Guha, 1999 en Chumbita, 1999: 88.

73 Esta perspectiva nos acerca así a los planteamientos de Sánchez y Meertens, 1982, quienes a la vez han enmarcado sus investigaciones sobre bandolerismo en los postulados teóricos de la corriente subalternista, especialmente en Gayatri Spivak. 
Así pues, de acuerdo con el análisis actual de la violencia en el continente, consideramos que «no es la pobreza, sino la desigualdad social, lo que genera más violencia» ${ }^{74}$. Entendemos esta desigualdad como la fractura o separación que se hace de un individuo de su comunidad política imaginada; de los valores, anhelos y problemas de su entorno. Las peculiares circunstancias de Arequipa en este periodo, generarían pues unas realidades sociales más orientadas a la integración y participación. Una identificación de cara a valores comunes que se iniciaría en el periodo virreinal mediante un proceso exitoso de asimilación al paradigma hispánico, y que, extendiéndose en los primeros años de la República, derivaría en un discurso constitucionalista y liberal ${ }^{75}$ en el que resonarían los ecos de esta «paridad cultural», reencauzada luego en una retórica republicana ${ }^{76}$.

\section{CONCLUSiOnes}

Diversas fuentes, como documentos administrativos, relaciones de gobierno, relatos de viajeros y - sobre todo- causas criminales, dan cuenta de la virtual inexistencia de bandolerismo en Arequipa a finales del periodo de la presencia española, situación que contrasta fuertemente con lo ocurrido en otros escenarios en el antiguo virreinato peruano y en Latinoamérica.

Las condiciones sociales y económicas de la intendencia de Arequipa no eran sustancialmente diferentes a las que se daban en otras áreas del virreinato. Sin embargo, esta zona se destaca por una tendencia a la isonomía cultural, étnica y económica. Paridad social que, por otro lado, se generó por la continua migración y reestructuración social, a causa de los terremotos y la bonanza económica iniciada a mediados del dieciocho. Observamos que, además de presentar una élite reducida y muy dependiente de sus relaciones con la plebe, la sociedad arequipeña mostraba por esos tiempos unas estructuras flexibles y dinámicas, que dieron lugar a cierta paridad en un sector plebeyo - poblacionalmente el mayoritario - que sostenía y proyectaba el discurso «oficial de civilidad» con fines de integrarse más perfectamente a la comunidad y ascender jerárquicamente en ella.

\section{Briceño-León, 2008: 111.}

75 Actitud que le reportaría el epítome de «Departamento de la Ley»

76 Chambers, 2003. La investigadora americana, entre otros estudiosos, alude al minifundio como una causa de difusión de la ciudadanía en sectores medios de la población. Además de uniformizar a los vecinos de la ciudad, el minifundio reforzaría de la auto-representación de muchos vecinos de medianos ingresos como parte del sector propietario, generándose una difusión del ideal de ciudadanía en sectores amplios. 
Consideramos, asimismo, que la adscripción muy generalizada de los códigos de policía por parte del mayoritario sector plebeyo arequipeño dio lugar - entre otras cosas - a la muy poca incidencia de bandas de asaltantes. Facinerosos que totalmente desligados de los valores de convivencia - sus expectativas, criterios y marcos de referencia- se habrían orientado al ataque manifiesto a su sociedad, en virtud a su situación de marginación. Algo que ocurría, al parecer, en las demás regiones del virreinato.

Finalmente, se hace necesario reflexionar sobre el marco teórico predominante en los trabajos que sobre bandolerismo se han llevado a cabo en el Perú; enfoques que mayoritariamente inspirados en visiones economicistas que dejarían de lado importantes aspectos culturales del fenómeno. El presente trabajo se orienta a remarcar la necesidad de un debate más profundo al respecto y de la flexibilización de las «claves hermenéuticas» utilizadas en la actualidad.

\section{FUENTES PRIMARIAS PUBLICADAS}

Barriga, Víctor, Memorias para la Historia de Arequipa. Relaciones de la visita al Partido de Arequipa realizada por el Gobernador Intendente don Antonio Álvarez y Jiménez 1786-1791. Tomo I, Arequipa, Editorial La Colmena S.A, 1941.

Barriga, Víctor, Memorias para la Historia de Arequipa. Relaciones de la visita al Partido de Arequipa realizada por el Gobernador Intendente don Antonio Álvarez y Jiménez 1793-1796. Tomo III, Arequipa, Editorial La Colmena S.A, 1948.

Carrión Ordóñez, Enrique, La lengua en un texto de la ilustración. Estudio Filológico de «La Noticia de Arequipa» de Antonio Pereyra y Ruiz, 1816, Lima, Pontificia Universidad Católica del Perú, 1983.

Fisher, John, Arequipa 1796-1811. La relación de gobierno del Intendente Salamanca, Lima, Seminario de Historia Rural Andina / Universidad Nacional Mayor de San Marcos, 1968.

Frías, Duque de (Bernardino Fernández de Velasco), Deleite de la discreción y fácil escuela de la agudeza, Madrid, Oficina de Franciscos Lorenzo Moxados, 1743.

Haenke, Tadeus, Descripción del Perú, Lima, Imprenta de El Lucero, 1901.

Terreros y Pando, Esteban, Diccionario castellano con las voces de ciencias y artes y sus correspondientes en las tres lenguas francesa, latina é italiana, Madrid, Imprenta de la Viuda de Ibarra, Hijos y Compañía, 1787.

Travada y Córdova, Ventura, El suelo de Arequipa convertido en cielo. Año 1752. Tomo I, Arequipa, Primer festival del libro arequipeño, 1958.

Unánue, Hipólito, Guía política, eclesiástica y militar del Virreinato del Perú para el año de 1793, Lima, Sociedad académica de amantes del país, 1793. 
Zamácola y Jáuregui, Juan Domingo, Apuntes para la historia de Arequipa, 1804, Arequipa, Primer festival del libro arequipeño, 1958.

\section{BIBLIOGRAFÍA}

Aguirre, Carlos, "Cimarronaje, Bandolerismo y desintegración Esclavista. Lima 1821-1854", Carlos Aguirre y Charles Walker (eds.), Bandoleros, abigeos y montoneros. Criminalidad y violencia en el Perú, siglos XVIII-XX, Lima, Instituto de Apoyo Agrario - P\&P, 1990: 137-182.

Andazabal, Rosa, Criminalística peruana en el siglo XVIII, Lima, Seminario de Historia Rural Andina - Universidad Nacional Mayor de San Marcos, 2007.

Aspell, Marcela, "Cárcel y presidios en Córdoba del Tucumán (siglo XVIII)", Alpanchis. Revista del Instituto de Pastoral Andina, 71 (Cusco, 2008): 211-270.

Blok, Anton, "The Peasant and the Brigand: Social Banditry Reconsidered", Comparative Studies in Society and History, 14/4 (Nueva York, 1972): 494-503. https:// doi.org/10.1017/s0010417500006824

Braudel, Fernand, El Mediterráneo y el mundo mediterráneo en la época de Felipe II, México, Fondo de cultura económica, 1976 [1949].

Briceño-León, Roberto, "La violencia homicida en América Latina”, América Latina Hoy, 50 (Salamanca, 2008): 103-116. Disponible en: http://www.redalyc.org/ pdf/308/30810929007.pdf [consultado el 21 de noviembre de 2017].

Brown, Kendall, Borbones y aguardiente. La reforma imperial en el sur peruano: Arequipa en vísperas de la independencia, Lima, Banco Central de Reserva del Perú - Instituto de Estudios Peruanos, 2008.

Buller, Carlos, Vinos, aguardiente y mercado. Auge y declive de la economía del vino en los valles de Arequipa (1770-1853), Lima, Quellca - Centro de Estudios Andinos, 2011.

Casey, James, The Kingdom of Valencia in the Seventeenth Century, Cambridge, Cambridge University Press, 1979.

Chambers, Sarah, De súbditos a ciudadanos: Honor, género y política en Arequipa, 1780-1854, Lima, Red para el desarrollo de las ciencias sociales en el Perú - Pontificia Universidad Católica del Perú, 2003.

Chávez Marquina, Juan Carlos, Control, resistencia y delito en la provincia de Trujillo en el declive del Antiguo Régimen (1784-1824), Tesis de licenciatura, Trujillo, Universidad Nacional de Trujillo, 2015. Disponible en: http://dspace.unitru.edu. pe/handle/UNITRU/1818 [consultado el 21 de noviembre de 2017].

Chumbita, Hugo, "Sobre los estudios de bandolerismo social y sus proyecciones", Revista de investigaciones Folclóricas, 14 (Buenos Aires, 1999): 84-91. Disponi- 
ble en: http://www.elortiba.org/old/pdf/chumbita245.pdf [consultado el 21 de noviembre de 2017].

Condori, Víctor, "Sociedad, identidad y regionalismo en Arequipa, 1780-1830", Historia, 9 (Arequipa, 2010): 47-71.

Durkheim, Emile, De la división del trabajo social, Madrid, Akal, 1987 [1893].

Durkheim, Emile, Las reglas del método sociológico, Madrid, Folio, 1999 [1895].

Condori, Víctor, Cuadernos de Historia de Arequipa. Cambio político y crisis económica en Arequipa a inicios de la República. 1825-1827, Arequipa, Ediciones Rhojita, 1987.

Condori, Víctor, Cuadernos de Historia de Arequipa. Cambio político y crisis económica en Arequipa a inicios de la República. 1825-1827, Arequipa, Ediciones Rhojita, 2012.

Espinosa Descalzo, Victoria, Cartografia de Lima (1654-1893), Lima, Seminario de Historia Rural Andina, Universidad Nacional Mayor de San Marcos, 1999.

Fernández Riquelme, Sergio, "El delito como Identidad social. Reflexiones sobre la comunidad y su proceso de integración", La Razón Histórica. Revista hispanoamericana de Historia de las Ideas, 35 (Madrid, 2017): 1-19. Disponible en: https:// www.revistalarazonhistorica.com/35-1/ [consultado el 23 de enero de 2020].

Fisher, John, Gobierno y Sociedad en el Perú Colonial: El Régimen de las Intendencias, 1784-1814, Lima, Pontificia Universidad Católica del Perú, 1981.

Fisher, John, El Perú Borbónico, 1750-1824, Lima, Instituto de Estudios Peruanos, 2000.

Flores Galindo, Alberto, "La ciudad sumergida. Aristocracia y plebe en Lima, 17501830", Obras completas, tomo III, parte II, Lima, Sur Casa de Estudios del Socialismo, 2010.

Fradkin, Raúl, "Bandolerismo y politización de la población rural de Buenos Aires tras la crisis de la independencia (1815-1830)", Nuevo Mundo Mundos Nuevos, 309 (París, 2005). https://doi.org/10.4000/nuevomundo.309

Guha, Ranajit, Elementary aspects of peasant insurgency in colonial India, Durham, Duke University Press, 1999.

Gutiérrez, Ramón, Evolución histórica urbana de Arequipa (1540-1990), Lima, Facultad de Arquitectura, Urbanismo y Artes de la Universidad Nacional de Ingeniería, 1992.

Hobsbawm, Eric, Rebeldes primitivos, Barcelona, Ariel, 1974 [1959].

Hobsbawm, Eric, Bandidos, Barcelona, Ariel, 1976 [1969].

Langer, Erick, "Bandolerismo andino y comunidad rural campesina. 1882-1930", Carlos Aguirre y Charles Walker (eds.), Bandoleros, abigeos y montoneros. Cri- 
minalidad y violencia en el Perú, siglos XVIII-XX, Lima, Instituto de Apoyo Agrario - P\&P, 1990: 248-276.

Lavallé, Bernard, Amor y opresión en los andes coloniales, Lima, Instituto de Estudios Peruanos, 1999.

Malamud, Carlos, "La consolidación de una familia de la oligarquía arequipeña: Los Goyeneche", Quinto Centenario, 49/4 (Madrid, 1982): 49-135. Disponible en: https:// www.semanticscholar.org/paper/La-consolidaci\%C3\%B3n-de-una-familia-de-laoligarqu \%C3\%ADa-Malamud/ccd0f52540fdcbb4f225e74108a23307a37a43ed [consultado el 23 de enero de 2020].

McCaa, Robert, "Calidad, Clase, and Marriage in Colonial Mexico. The Case of Parral, 1788-90", Hispanic American Historical Review, 64/3 (Durham, 1984): 477-501. https://doi.org/10.2307/2514936

Miró Linares, Fernando y Agustina Sanllehí, José (eds.), Crimen, Oportunidad y Vida Diaria. Libro homenaje al Profesor Dr. Marcus Felson, Madrid, Dykinson, 2015.

Moral Roncal, Antonio, "Honor, vileza y honra de los oficios mecánicos en el siglo XVIII", Baetica: Estudios de arte, geografía e historia, 18 (Málaga, 1996): 379386. Disponible en: https://dialnet.unirioja.es/descarga/articulo/95356.pdf [consultado el 21 de noviembre de 2017].

Moreno Sandoval, Armando, "El bandolerismo social revisitado. El caso del Norte del Tolima (Colombia)", HISTOReLo. Revista de Historia Regional y Local, 7 (Medellín, 2012): 271-309. https://doi.org/10.15446/historelo.v4n7.24603

Muir, Edward, Mad Blood Stirring. Vendetta and Factions in Friuli During the Renaissance, Baltimore, John Hopkins University Press, 1998.

Sánchez, Gonzalo y Meertens, Donny, Bandoleros, gamonales y campesinos. El caso de la violencia en Colombia, Bogotá, El Áncora Editores, 1982.

Slatta, Richard (ed.), Bandidos: The Varieties of Latin American Banditry, Connecticut, Greenwood Press, 1987.

Stavig, Ward, "Violencia cotidiana de los naturales de Quispicanchis, Canas y Canchis en el siglo XVIII", Revista Andina, $3 / 2$ (Cusco, 1985): 451-468.

Stavig, Ward, "Ladrones, Cuatreros y Salteadores. Indios criminales en el Cuzco rural a fines de la colonia", Carlos Aguirre y Charles Walker (eds.), Bandoleros, abigeos y montoneros. Criminalidad y violencia en el Perú, siglos XVIII-XX, Lima, Instituto de Apoyo Agrario - P\&P, 1990: 69-103.

Torres i Sans, Xavier, "El bandolerismo mediterráneo: una visión comparativa", Ernest Belenguer (coord.), Felipe II y el Mediterráneo, Vol. II, Madrid, Sociedad Estatal para la Conmemoración de los Centenarios de Felipe II y Carlos V, 1999: 397-423.

Torres i Sans, Xavier, "Faida y bandolerismo en la Cataluña de los siglos XVI y XVII", Diritto@Storia, 2 (Sassari, 2003). Disponible en: http://www.dirittoestoria.it/ 
lavori2/ Contributi/Torres-Faida-bandolerismo.htm\#_ftn1 [consultado el 13 de marzo de 2018].

Vargas Ugarte (S.J.), Rubén, Historia General del Perú, Tomo VI, Emancipación (1816-1825), Lima, Carlos Milla Batres, 1966.

Vivanco, Carmen, "Bandolerismo colonial peruano: 1760- 1810. Caracterización de una respuesta popular y causas económicas", Carlos Aguirre y Charles Walker (eds.), Bandoleros, abigeos y montoneros. Criminalidad y violencia en el Perú, siglos XVIII-XX, Lima, Instituto de Apoyo Agrario - P\&P, 1990: 24-56.

Walker, Charles, "Montoneros, Bandoleros y Malhechores: Criminalidad y política en las primeras décadas republicanas", Carlos Aguirre y Charles Walker (eds.), Bandoleros, abigeos y montoneros. Criminalidad y violencia en el Perú, siglos XVIII-XX, Lima, Instituto de Apoyo Agrario - P\&P, 1990: 104-136.

Zegarra, Guillermo, Arequipa, en el paso de la Colonia a la República. Visita de Bolívar, Arequipa, Cuzzi y Cía. Impresores, 1973.

Fecha de recepción: 4 de diciembre de 2017.

Fecha de envío de las modificaciones: 8 de marzo de 2018.

Fecha de aceptación: 19 de marzo de 2018.

\section{The reasons behind the absence of banditry. The case of Arequipa towards the end of the viceroyalty (1780-1824)}

This article analyses the causes of the absence of banditry in Arequipa towards the end of the Spanish presence in Peru, using the administrative and criminal sources available. Considering the changes in socioeconomic structure in the southern region of Peru due to the Bourbon Reforms, the causes that explain this phenomenon are interpreted by comparison with other areas of the viceroyalty. In addition, Peruvian historiographic perspectives on banditry are examined - many of which focus on economic considerations - with a view to reinterpreting these criminal acts from a more cultural standpoint.

KeY WORDs: Banditry, Bourbon Reforms; Arequipa. 